\title{
Kürt Atasözlerinde Kadın İmajı (Kuzey Irak Örneği)
}

The Image of Women in Kurdish Proverbs (Northern Iraq example)

\section{Ranja Abdalla Saeed*}

Öz

Kültür, tarih boyunca insanoğlunun yarattığı, ürettiği maddi ve manevi olan gelenek, görenek, değer, inanç, örf, adet, mimari, sanat, hüner, teknoloji vb. tüm değer içerikli unsurları kapsamaktadır. Kültür bu özelliğiyle aktarılan bir şeydir. Bir toplumu anlamak için onun kültürünün incelenmesi gerekir. Dil de kültürün temel ögesi olarak yazılı ve sözlü şekilde kültür aktarımında rol oynamaktadır. Bu çerçevede bir ulusun ortak düşünce, kısa ve özlü sözleri içine alan atasözleri, toplum ve kültürün zihniyetine dair önemli veriler taşımaktadır. Bu çalışmada bir halk olarak Kürtlerin, atasözlerindeki kadın imajının nasıl yer aldığı araştırılmaktadır. Bu amaçla Kuzey Irak'ta yaşayan Kürt halk atasözlerindeki kadın imajı, sözlüklerin taranması ve betimsel analiz yöntemi ile anlaşılmaya çalışılmıştır. Bu amaçla kadınların bulunduğu bütün pozisyon ve sosyal statüler ' $k ı z$ çocuk, genç kız, kadın, avrat, karıkoca, anne, kız kardeş, dul, yaşlı kadın, kaynana, elti, görümce, gelin' gibi terimlerle ele alınmaktadır.

Anahtar Kelimeler: Kürt, kadın, imaj, kuzey ırak, atasözü, kültür.

\footnotetext{
`Sakarya Üniversitesi, Sosyoloji Bölümü Yüksek Lisans Öğrencisi

Bu makale iThenticate sistemi tarafından taranmıştır.

Makale Gönderim Tarihi: 1 Ağustos 2018
} 


\begin{abstract}
Culture combines both material and spiritual traditions, customs, values, beliefs, architecture, art, trickery, technology, etc. Produced and created by human beings throughout history. And it covers all value-added elements. In order to understand a society it is necessary to examine its culture, language also conveys culture in written and verbal form as the basic element of the culture. In this framework, every nation has its proverbs, the society and the culture mentality that include common thought, short and concise words. The main problematic of this study is to investigate how women and women's image are presented in Kurdish proverbs. For this purpose, a method of descriptive analysis has been used for understanding the proverbs of Kurdish people living in northern Iraq. In this case, all positions and social statutes of women such as 'daughter, girl, sister, woman, couple, mother, widow, old woman, mother-in-law, sister, sister in-law, husband's sister, bride'; such terminologies were analyzed.
\end{abstract}

Keywords: Kurdish, women, image, northern Iraq, proverb, culture. 


\section{Giriş}

Taylor'a göre kültür; ahlak ve alışkanlık gibi manevi ögeleri kapsayan ve birey tarafından kazanılan karmaşık bir bütündür (Haviland ve diğerleri, 2008: 103). Kültür dinamik, değişken bir yapıya sahiptir ve öğrenilerek nesilden nesile aktarılma hususiyetine sahiptir (Tezcan, 2008: 6). Kültürün diğer özeliklerine bakıldığında da, birey toplum içinde yaşadığından dolayı kültürlenme yoluyla kendi kimliğini kazanır ve bu kimlikle toplum ve kültür içerisinde varlığını gerçekleştirir. Başka bir açıdan bakıldığında kültür, toplum içindeki bireyin kültürlenme süreciyle kendi kimliğini kazanmasını ve bu kimlikle toplum içerisinde bir yer edinmesini sağlar. (Tok, 2003: 28). Dolayısıyla örf, adetler ve kültürün diğer ögelerinin hep beraber bir araya gelmesiyle bireyin kişiliği oluşur ve böylece kişinin kimliği de bu zeminde kurulur. Kültür, bir toplumsal formasyon olarak basitten karmaşığa her toplumda benzer özelliklere sahip olmakla birlikte kültürün sahip olduğu değer sistemi değişkenlik göstermektedir.

Kültürün öğrenilme ve aktarılma sürecinde başrolü oynayan yegâne araç dildir. Ziya Gökalp, dilin, kültürün kapısı ve temel ögesi olduğunu ifade eder. Kültürün sembolik yapısı ile dilin işleyişi arasında güçlü bir ilişki vardır (Mengü, 2003; Kaplan, 2006). Aksan'a göre "Dil; düşünce, duyu ve isteklerin bir toplumda ses ve anlam yönünden ortak olan ögeler ve kurallardan yararlanılarak başkalarına aktarılmasını sağlayan, çok yönlü, çok gelişmiş bir dizgedir." (Tezcan, 2008: 159).

Edward Sapir (Ünalan, 2012: 2) dili, ürettiği semboller sistemi vasitasıyla duygu ve zihniyeti aktarmaya yarayan bir araç olarak nitelemektedir. Saussure'e göre (2013: 71); “Dil, hem konuşma yetisine sahip olmanın doğurduğu toplumsal bir üründür hem de bireylerin bu yetiyi kullanabilmeleri için toplumsal bir teşekkülün benimsediği zorunlu uzlaşımların bütünüdür". Bunlara göre dil tamamen sosyal bir araçtır, bir toplum içerisinde doğar ve dil aracılığıyla kurulan anlam, yine o topluma göre belirlenmektedir. Dil yeteneği insan içinde mevcuttur Dili kullanmak, bireyde doğuştan bulunan bir yetidir, ama bu yetenek ancak toplum içinde açığa çıkabilir. Dolayısıyla başta aile olmak üzere sosyalizasyo- 
nu sağlayan bütün toplumsal kurumlar, kültürün aktarılmasını mümkün kılan dilin hayatî işlevini yerine getirmesinde önemli rollere sahiptir.

'Dil' ve 'Kültür' karmaşık bir ilişki içindedir; zira dil; cinsiyet, s1nıf, yaş gibi bir çok toplumsal değişken tarafından belirlenmektedir. Bu faktörler bir dilin aynı kültür içinde dahi farklı karakterler taşımasına neden olur. Dolayısıyla bir toplumun kültürünü, kendi dili üzerinden anlamaya çalıştığımızda homojen bir yapıdan ziyade farklılıklar arz eden bir yapıyla karşılaşırız. Bu çerçevede bir toplumun zihniyet dünyasını anlamak istiyorsak, o toplumun kültürüne derinden vâkıf olmamız gerekmektedir. Dil, kültürün asası olduğuna göre dil içerisinde geçen bütün kelime, konuşma ve simgelerin hepsi kültürün farklı bir tezahürüne işaret eder. Yani, kapsamlı bir kültür analizi, dili bütün yönleriyle olmasa da, onu bir çok farklı açıdan ele almamızı gerektirir.

Oakley'e göre "cinsiyet", biyolojik olarak kadın-erkek ayrımını anlatırken; "toplumsal cinsiyet"(gender), kadınlık ile erkeklik arasındaki toplumsal ve kültürel bakımdan yapılan ayrımı ifade etmektedir. O'na göre, toplumsal cinsiyet bir kültür meselesidir ve kadınlar ile erkeklerin "dişil" ve "eril" olarak sosyal sınıflandırılmasına işaret etmektedir. Bu sinıflandırmalar kültüreldir, yere ve zamana göre değişiklik gösterir (Güney ve Bener, 2011: 167).

Buna göre toplumsal cinsiyet, kültür tarafından belirlenmektedir ve yine kültürün yeniden üretim süreçleri aracılığıyla diğer kuşaklara aktarılır. Dolayısıyla kültür aktarımını sağlayan en temel araçlardan biri olan 'dil'e baktığımızda; dilin bazı yaygın formları dolayımıyla 'toplumsal cinsiyet'in nasıl inşa edildiğini ve yeniden üretildiğini inceleyebiliriz. Bunlardan en önemlisi atasözleridir; çünkü kültürün aktarılmasında ve yaşam tarzının gösterilmesinde en sadık şekilde toplumun gerçek tarih, gelenek, görenek, değer ve tutumlarını göstermektedir (Özkan ve Gündoğdu, 2011: 1133). Örneğin, bir toplumda hâkim olan eril dil; kültürün dil üzerinde ne kadar güçlü bir etken olduğunu gösterir. Aynı zamanda dil de yeniden bu kültürü üretmekte, erkek egemenliği ve cinsiyetçi söylemleri yeniden meydana getiren erkek dili, kültür ve toplum üzerinde açık seçik etkisini gösterebilmektedir (Erden, 2011: 604). 
Atasözleri, öğüt verme ya da ibret alma amacı taşıyan, ortak düşünceyi ifade eden kısa, özlü ve kalıplaşmış sözler olarak tanımlanabilir. Başka bir deyişle atasözleri sadece öğüt verme işlevini görmez; toplumsal olay ve olgular hakkındaki atasözleri vasıtası ile bir söylem inşasını da mümkün kılar. Atasözleri geçmişte ifade edilen sözler olmasından dolayı o dönemdeki zihniyeti anlamak için de önemli bir role sahiptir. Dolayısıyla toplumun sistemini oluşturan siyaset, ekonomi, din vb. alanlara dair anlayışları atasözleri yardımıyla incelememiz mümkündür.

Geçmişten gelerek günümüze ve sonraki kuşaklara ulaşan ve daha çok mecazi deyişler içeren atasözleri; toplumun hafızası olma işlevini görmektedir. Yine atasözleri toplumsal değerleri, örf ve alışkanlıkları muhafaza ederek bunların nesilden nesle aktarılmasını sağlamaktadır (Güleç, 2002), (Albayrak, 2009), (Artun, 2015). Atasözlerinin özelliklerinden birisi anonim olmalarıdır, elbette başta bireyler tarafından söylenmiştir; ancak toplumda karşılık bulmasından sonra bu sözler, atasözü olmuştur. Genellikle kısa olan fakat derin anlamlar içeren atasözleri, halkın hayat tecrübesi ve kolektif hafızası olarak uzun süre boyunca etkisini kaybetmeden süregelmektedir. Atasözleri aracılığılla bir milletin düşünce, yaşayış ve geleneklerine vakıf olmak, onun kültürel kimliği hakkında esaslı bir bilgi birikimine ulaşmak mümkündür.

\section{Araştırma Yöntemi}

Atasözleri bir toplumun kültürel mirasıdır ve bir birikim sonucu oluşarak günümüze kadar ulaşmıştır ve toplumun zihniyetini gösterir, bireysel değil, kolektif bir bilincin ürünüdür. Bu kapsamda, kadın imajının Kürt atasözlerinde nasıl sunulduğu ortaya konulmaya çalışılacaktır. Bunu gerçekleştirmek amacıyla betimsel analiz yöntemi kullanılmıştır. Betimsel analiz yöntemine göre elde edilen veriler daha önce belirlenen temalara göre özetlenir ve yorumlanır, aynı zamanda bulgular sistematik, düzenlenmiş, açık ve yorumlanmış bir biçimde betimlenip takdim edilir. Bununla birlikte neden-sonuç ilişkileri irdelenerek birtakım sonuçlara ulaşılır (Yıldırım ve Şimşek 2013: 256).

Araştırmanın evreni, Kuzey Irak'ın Kürt bölgesinde yaşayan in- 
sanların kullandığı Kürtçe (Sorani lehçesi)'ye ait olan atasözleridir. Bu araştırmada incelenecek atasözlerini belirleyebilmek amacıyla, içinde kadınla ilgili ifadelerin geçtiği atasözleri taranmıştır. Bu amaçla (Şarazuri, 2010), (Ali, 1972), (Xal, 2014), (Lek, 2012), (Reşaş, 2010), (Osman, 2010), (Helebceyi, 2014) olmak üzere yedi tane Kürtçe atasözleri sözlüğü taranmıştır. Kadınlara dair bir çok biyolojik ve sosyal durumu ifade eden terimleri (kız çocuk, genç kız, kadın (genel isim olarak), avrat, kız kardeş, karıkoca, anne, dul, yaşlı kadın, kaynana, elti, görümce, gelin) ve göndermeleri içeren atasözleri toplanmıştır.

$\mathrm{Bu}$ çalışmada söz konusu Kürt atasözlerinden hareketle Kuzey Irak Kürt toplumundaki kadın imajı üzerinde durulmaya çalışılacaktır. Toplamda 223 adet atasözü ele alınmıştır. Betimsel araştırmalarda sıkça yapıldığı gibi önceden konuyla ilgili en yaygın şekilde bulunan atasözleri belli başlıklar altında sıralanıp incelenmiştir. Bu araştırmanın amacı kadınlığın Kürt toplumunda ne anlama geldiğini ve kadın imajının bu toplumda nasıl olduğunu anlamaya çalışmaktır. Aynı zamanda Kürt toplumunun zihniyetinin ve kültürünün geçmişte nasıl olduğunu göstermektir.

\section{Kız Çocuk Bağlamındaki Atasözleri}

\subsection{Aile İçerisinde Kız Çocuk Hususiyetleri}

Kız çocuk, ailenin unsurlarından biri olarak atasözlerinde sık sık geçmektedir. İncelenen atasözlerine bakıldığında aile içerisinde kızın değeri babasının varlığıyla anlam kazanır. Kız çocuk sahibi olmak aile içerisinde 'gurur verici' bir şey değildir. Ve babaya nisbet edildiği ölçüde değer kazanabilir.

Kimi atasözlerinde kızların terbiye edilmesi için dayağın bir araç olarak kullanılabileceği dile getirilmiştir. Yine bazı atasözleri ailedeki kız sayısının artmasına olumsuz anlam yüklemektedir. Hatta çok sayıda kız çocuğun bulunduğu evlerin boş gibi olduğuna dair ifadeler kullanılmıştır. Bunun nedeni iki açıdan açıklanabilir: birincisi, aile içerisinde kızın var olması pek azametli ve gurur duyulacak bir şey olarak görülmez, ikincisi ise kadınların bir araya gelmesi hoş karşılanmaz; örneğin bir atasözünde kadınların sayıca çok olduğu yerler için kadınlar hamamı benzetmesi kullanı- 
lır. Kimi zaman ise atasözlerinde kız çocuk; kaleye benzetilmiştir; yani burada kız çocuğu ulaşması güç ve korunaklıdır.

1. "Babasız kız çitsiz bostan gibidir; güzelliğinin değeri olmaz."

2. "Kız kaledir, elde etmesi pek güçtür."

3. "Annesiz kız, duvarsız bahçe gibidir."

4. "Kendi kızını, elin oğluna feda etme."

5. "Kız, halkın malıdır, oğlan altın gibidir."

6. "Kızını dövmeyen, dizini döver."

7. "Yalnız kız çocuklarıyla dolu ev; boş evdir."

\subsection{Kız Evladının Evlenme Çağı ve Süreciyle İlgili Atasözleri}

Atasözlerinde kız çocuğunun genç yaşta evlendirilmesi gerektiği tavsiye edilmektedir. Kürt toplumunda önceki dönemlerde "görücü usulü"nün egemen evlenme biçimi olmasından dolayı kız, istenilen ve alınan konumundadır.

“Kız köprü gibidir, herkes üzerinden geçer."

Bir genç kızın evlilikten önce herhangi bir erkekle bağı bulunmasın, erkeklerin tuzaklarına düşmesin diye erken evlenmesi tavsiye edilmiştir. Bu görüşe göre genç kızlar yetiştiği zaman çapkınlığa başlamaktadır. Bu durum ise toplum tarafından hoş karşılanmaz, çünkü bu toplumdaki neredeyse bütün erkekler bakire bir genç kız ile evlenmek istemektedir. Kimi zaman atasözlerinde anne tarafından kızına yönelik söylenen sözlerde bu durumun tam tersi görülür. Bu sözlerde kızın daha genç ve çocuk olduğu belirtilmek istenir.

8. "Oynamayan ağaç olmaz, çapkınlık yapmayan kız olmaz."

9. "Kızı oynaşmaya başlamadan al."

Genç kızın kendi zamanında evlenmesi gerektiği vurgulanmıştır. Zamanında evlenmeyen genç kız için kokmuş, çürümüş ve yıpranmış gibi negatif anlamlarla yüklü birtakım ifadeler kullanılır.

10. "Zamanında evlenmeyen kızın bir kanadı kırıktır."

11. "Kız ve balık çok beklerse kokmaya başlar." 


\section{2. "Kız kavun gibidir, kalırsa çürür."}

Bazı atasözlerinde, kızın evlenmeden önce hazırlanması gerektiği vurgulanmıştır. Bu doğrultuda hazır olmayan kız, kadın olamaz. Bazı sözlerde ise evlilik hayatının kadın için ne kadar zor olduğu vurgulanir.

13. "Kızını evde sına sonra dağın başına gönder."

14. "Her kız evlenir, ama her gelin kadın olamaz."

15. “Evlenene kadar mirsin, evlendiğinde vezirsin, hamile olduğunda yaşlısın."

Atasözlerine göre kız, evlilik çağına geldiğinde evlenme kararının babası tarafından onaylanması gerekir. Ele aldığımız bir atasözünde ise; "Annesini ikna et, kız senindir." ifadesinde kızın annesinden alınabileceği söylenir. Bu iki atasözü karşıt durmakla birlikte aile içerisindeki ilişkilerin farklılığını da imâ eder. Aslında aile içerisinde perde arkasında olaylar kadın tarafından yönetilmekte, fakat görünürde aile, erkekler tarafından yönetilmektedir. 16. "Tüy gibi kara olsam da babamın kudreti beni evlendirebilir." Erkekler için eş seçiminde bakire kız yaşlı olursa bile tavsiye edilmektedir. Çünkü daha önce evlenmeyen bakire kız; temiz, saf, sahtecilik yapmayan biri olarak görülmektedir. Kadınlar için de benzer bir durum söz konusudur; onlar da daha önce hiç evlenmemiş bir erkekle evlenme isteğini atasözlerinde dile getirmiştir.

17. "Yol olsun, uzak olsun, kız olsun yaşlı olsun."

18. "Eğer evlenmek istiyorsan kız al, eğer tahıl satın almak istiyorsan buğday al."

19. "Kız olsun, ayı olsun."

20. "Kızla evlen, başını derde sokma."

21. "Her öğünüm ekmekle çamur olsun, bir şartla kocam oğlan olsun."

\subsection{Kız ve Oğul Ayrımcılığıyla İlgili Atasözleri}

Kürtçede ve özellikle atasözleri içinde ayrımcılık yapan sözler ve 
ifadeler mevcuttur. Kimi zaman biçimsel olarak incelenen atasözlerine bakıldığında kız ve oğul bağlamında kurulan atasözlerinde "önemli" ve "önemsizlik" söz konusudur.

67. “O adamın oğlu ölmesin de kıza bir türlü çare bulur.”

Oğlan, Kürt atasözlerinde kalıcı, cesur ve mülk/zenginlik çağrışımlarına sahiptir. Geniş ailede birlikte yaşayan insanların ve akrabaların sayısı çok, kan bağı yoluyla birbirine bağlanmıştır (baba akrabalığı: kardeşler, amcalar, büyükanne ve büyükbaba). Burada ataerkil bir yapı olduğundan dolayı sadece belli bir atadan olan akrabalar hep birlikte belirli bir toprak parçası üzerinde yaşamaya çalışmışlardır. Kürt toplumunun 20.yy.'a kadar geniş ailelerden oluştuğu tespit edilmektedir. Erkek evlendikten sonra bu geniş aile içinde kaldığı, soyun devamını sürdürdüğü, ekonomik açıdan ailenin geçimini sağladığı, aile sıkıntı ve kavgaya düştüğünde hep erkeklerin aileyi koruduğu Kürt atasözlerinde görülebilmektedir.

Buna karşılık kızlar aile içinde kalmadığından dolayı, evlendiğinde eşinin izini takip ettiği için ata tarafından önemsenmemiştir. Ama diğer taraftan ev içindeki işlerin kadınlar ve kızlara düştüğünü görmek mümkündür, aynı zamanda kan bağlılığı amacıyla iki aile arasında ilişki kurmak için kızın çok önemli görüldüğü tespit edilmektedir. Bu konuyla ilgili atasözlerine bakıldı̆̆ında, oğul babanın mirasını alır, bu miras erkeklerin yanında kaldığından aynı elden sayılır, ama kız bu mirası aldığında mülkiyet kaybolmuş olur, dolayısıyla kız babanın mirası için bir talancı olarak görülmüştür. Kimi atasözlerinde insanın ahlâkî konumu, kız ve oğul karşıtlığı üzerinden değerlendirilmektedir.

68. "Kız halkın malı, oğul babanın malıdır."

69. "Oğlumuz dal olsun, babanın gözünü çıkarsın."

70. "Erkek mülktür, kızsa su gibidir; gelip geçer."

71. "Söz dinleyen kız, nazlı erkekten yeğdir."

Yine bazı Kürt atasözlerinde, bir kimse için hayır duası edilirken o kişinin ilk çocuğunun bir erkek evlat olması temennisi ifade edilir.

72. "Ahiretin hayırlı olsun, ilk doğanın oğul olsun." 
73. "Eğer oğulsa Allah dört gözden ayırmasın, eğer kızsa Allah ne vermişse hayırlısıdır."

\subsection{Kız ve Erkek Kardeşin Arasındaki İlişkiyle İlgili Atasözleri}

Aile içerisinde bir ebeveynden gelen çocuklara, kan bağlarıyla birbirine bağlı olan, anne ve babayla yaşayanlara kardeş denilmektedir. İncelenen atasözlerine bakıldığında erkek kardeşin, kız kardeşe göre daha önemli olduğu belirtilmektedir. Bunun sebebi ise; erkeklerin kız kardeşlerini koruması ve para kazanarak ailesine yardım etmesidir. Aynı zamanda kızın, erkek kardeşlere göre daha önemli olduğunu ifade eden atasözleri de mevcuttur. Bunlara göre kız kardeş yemek pişirme, elbise yıkama gibi ev iş ve hizmetleri için çok büyük rol oynar.

74. "Erkek kardeş çobanlık yapar ama onu yine kız kardeş bekler."

75. "Yapraksız ağacın değeri olmaz, erkek kardeşi olmayan kızın güzelliği olmaz."

76. “Erkek kardeşsiz kız, fenersiz ev gibidir."

77. "Başörtüsüz ev, hiç olmasın daha iyidir."

Bazı atasözlerinde ise erkek ve kız kardeşler arasında güçlü bağlar olmasına rağmen ister kız olsun ister erkek; kardeşler için evlenmenin daha farklı bir anlam taşıdığı ifade edilir. Bunun bir tezahürü atasözlerindeki; kız kardeş ile erkek kardeşin, son kertede birbirine yetmeyeceği imâsında görülebilir. Çünkü her biri evlendikten sonra kendi yuvasında eşiyle beraber yaşamını sürdürmektedir.

78. "Kadın, kısrak ve tüfek kimin yanındaysa onundur."

79. "Ne ateş, ne çift; hiç birisi evlenme gibi olmaz."

80. "Ateş hoştur, çiftli hoştur; erkek kardeş iyidir, ama evlenme kadar değil."

\section{Kadının Toplumsal Konumuna Dair Atasözleri}

Bu alt bölüm, atasözlerinde ve dolayısıyla Kürt toplumunda kad1nın sosyal ve fizikî yaşantısının nasıl yorumlandığını ele almaya 
çalışmaktadır. Kadından dul, yaşlı ve avrat olarak bahsedilen atasözleri, bu bölümde incelenmeye çalışılmıştır.

\subsection{Kadın Kelimesi Geçen Atasözleri}

Kürt atasözlerine bakıldığında en çok söylenen atasözleri kadınlara yönelik sözlerdir. Bu doğrultuda çoğu atasözünün erkekler tarafından söylendiğini belirtmek mümkündür. Aynı zamanda kadınların söylediğini düşündüğümüz atasözlerinin de olduğu görülmektedir. Erkeklerin ağzından söylenen bu atasözlerinin bir düşünceden ziyade bir yargı oluşturduğu söylenebilir. Geçmişten bugüne Kürt atasözlerinde kötü ve iyi kadın arasında çizgi çizildiği ve bütün kadınların bir bakışta değerlendirilmediği görülmektedir. Bununla birlikte toplum açısından iyi olanlara yönelik yüceltici ve övücü sözlerin kullanıldığı görülürken, diğer taraftan kötü olanlara karşı aşağılayıcı ve küçültücü sözlerin kullanıldığı dikkat çekmektedir. Burada "iyi kadın" algısına bakıldığında, eril toplumsal yapının belirlediği şemaya uygun olarak davranan kadın karakteri göze çarpmaktadır.

Atasözlerinde sürekli olarak iyi kadının istenildiği ve kötü kadından şikâyette bulunulduğu görülmektedir. Bunun yanı sıra, iyi kadın motifi; arzu edilen, hayat ve nimet gibi değerli kavramlarla ifade edilirken kötü kadın motifi; acı, azap, ah, hoşa gitmeyen kimse ve nefret edilen şey gibi ifadelerle tarif edilmiştir.

90. "Kadın var, azap var."

91. "Bazısı kadındır, bazısı acıdır, bazısı ise fitne fesat çıkarandır."

92. "İyi kadın hayattır, kötü kadın acıdır."

93. "İyi kadın nimettir, kötü kadın nefrettir."

94. "Keşke iyi kadına, uf kötü kadına aittir."

Kürt atasözlerinde kadına yönelik bir takım negatif hükümlerin olduğu görülmektedir. Bunlardan biri kadının, akıllıca davranmayan ya da aklı başında olmayan bir varlık olarak nitelenmesidir. Kadının aklının kucağında olduğu söylenilmiştir, yani böyle bir deyişle; kadınların rasyonel davranışlardan çok içgüdüsel davranışlar sergilediği dile getirilmek istenmiştir. 
95. "Erbezimin aklı ve kadının (eşimin) aklı aynıdır."

96. "Kadının aklı kucağındadır."

97. "Kadınla müşavere et, ama sözünü küpe gibi kulağına takma."

98. "Kadının saçı uzun aklı kısadır."

Kadını akılsız olarak tarif eden atasözlerinde kadınların aldatılabilen varlıklar olarak görülmesi dikkat çekmektedir. Bu sözlerde genellikle kadının saf olduğu, yalana çabuk inandığı imâ edilmektedir. Kadın; zor durumlarda dahi kendi güzelliğiyle ilgilenen ve diğerlerinin acılarını önemsemeyen acımasız bir varlık olarak nitelendirilmiştir. Kadınların sır tutamamasının onların çok ve boş konuşmasından kaynaklandığı iddia edilmiştir. Böyle tanıtıldığından dolayı kadınların sessizliğine de şüpheyle yaklaşılmıştır. Kadınların şeytana benzetilmesi kadının kurnazlığıyla açıklanmıştır. Sürekli evde kaldığından dolayı kocasının dikkatini çekmek için yüz türlü hile yaptığı düşünülmüştür. Bütün bu sözlerde temel olarak kadın, çözümlenemeyen ve anlaşılamayan bir dügüum olarak görülmektedir. Dolayısıyla bir nevi mutlak kötü olarak anlatılagelen kadına karşı şiddet meşrulaştırılmıştır.

99. "Kadın nedir! Bir ruj ve aynayla aldatabilirsin."

100. "Kadın şüpheci ve saftır."

101. "Atasından yedi kişi ölse de sürme çekmeyi bırakmaz."

102. "Sessiz kadına ve çok havlayan köpeğe inanma."

103. "Sırrını lal bir kadının yanında beyan edersen yine ortaya çıkar."

104. “Çölün suyuna ve evin kadınına güvenme."

105. "Kadının hâkim olduğu yerde şeytan hizmetçisidir."

106. "Kadın düğümdür, kimseye açlamaz."

Kürt atasözlerinde bir şekilde, kadının toplum tarafından uyarılması için ve iyiliği telkin amacıyla yapılmış bazı göndermeler dikkat çekmektedir. Öncelikle kadının güzel ve hoş olması gerektiği sıklıkla belirtilmiştir. Bunun yanı sıra kadından utanması ve gücenmemesi beklenmiştir, aynı zamanda kadının güler yüzlü ve namuslu olmasının tavsiye edilmesi söz konusudur. 
107. "Utanmaz kadın tuzsuz yemek gibidir."

108. "Kadın gücenirse alçaklaşır."

109. “Utangaç kadın değeri bir şehir gibidir, utangaç erkek beş para etmez."

110. “Kadının güzelliği tebessümüdür, erkeğin güzelliği tatlı dilindedir."

111. "Kadının güzelliği göz önündedir, hayâ ve namusu gönül içindedir."

Atasözlerine baktığımızda kadının devamlı olarak yapması gereken yegâne iş ev işleridir. Evin sorumluluğunu üstelenen, temizlik yapan, kocasına ve çocuklarına bakan kadından, atasözlerinde evin direği ve ekonomik açıdan hazinesi olarak bahsedilmektedir.

112. "Ağırbaşlı kadın kâşanede koy."

113. "Aslan ininden çıkarsa ister er ister dişi olsun."

114. "Ev ve ailenin güzelliği kadınladır."

115. "Kadın evin direğidir."

116. "Evle kadın birlikte anılır."

117. "Para deredir, kadın hazine."

\subsection{Avrat Kelimesi Bağlamında Bulunan Atasözleri}

Kürt dil ve literatüründe avrat kelimesi kadının eş anlamlısı olarak kullanılmıştır. Diğer taraftan bakıldığında bu kelimeye daha dini ve İslami bir anlam yüklendiği görülmektedir. İncelenen atasözlerinde 'avrad'ın güzelliği ahlakla bağdaştırılmaktadır. Toplumsal cinsiyet açısından bakıldığında ister evin idarecisi ister Allah'ın en değerli armağanı olarak nitelendirilsin avrat; erkeğin görüşlerine göre şekillendirilmektedir.

118. "Avradın güzelliği ahlak ve huyuyla ölçülür.”

119. "Avrat, evin idarecisidir."

120. "Kocasına dostluk gösteren avrat, kendine dostluk yapar."

121. "Allah'ın en değerli armağanı erkeğe avrattır." 
Kimi zaman avrat şeytanın kendisi veya şeytanın hocası olarak görülmüş̧tür. Kanımızca bunun sebebi; kadının erkeğin cinsel duygularını uyarması ve intikamcı olarak görülmesi dolayısıyladir.

122. "Dün seni seven avrat, bugün sana tapınır, yarın ise sana ihanet eder."

123. "Dün ayağın önünde ağlayan avrat, yarın seni ayağının önünde ağlatır."

124. "Şeytan erkeğin hocası, avradın öğrencisidir."

125. "Avradı görünce al yanağına bakma, şeytandır."

Bazı atasözlerinde intikamcı yerine karşımıza çıkan, duygusal ve zayıf bir varlık olarak tanıtılan avrat, bir öpücükle kontrol altına alınabilmektedir. Dolayısıyla böyle duygusal ve zayıf görülen kadının pek fazla zararının olamayacağı ifade edilmektedir. Çünkü bu anlayışa göre kadının, duygusal bir doğası olduğuna inanıldığı için verebileceği zararın da önemsiz olduğu düşünülür.

126. "Avrat yılandır, ama zehirsizdir."

127. "Çok güzel olan avrat, ayağa dikendir."

128. "Avratla duyguluca konuş, akıldan daha iyi."

129. "Avradın en büyük silahı gözyaşlarıdır."

130. “Avradın birinci öpücüğü üzengi, ikincisi saraç, üçüncüsü yulardır."

\subsection{Dul Kadın Hakkındaki Atasözleri}

Kürt atasözlerinde dul kadının iki şekilde tarif edildiği görülmektedir. Birincisi, eşi herhangi bir sebeple ölmüş olan kadındır. İkincisi ise, eşinden boşanmış olan kadındır. Evlenme çağına gelen erkeklere tavsiye niteliğinde söylenmiş olan atasözlerine baktığımızda eş seçiminde bakire kızların tercih edilmesi tavsiyesini görürüz. Bu anlayış dul kadınların eş olarak tercih edilmemesini salık vermektedir. Dolayısıyla kadının değerinin, bir bakıma medenî hâlinin öncelenerek belirlendiğini söyleyebiliriz.

Aynı şekilde bu ataerkil sosyal yapıda boşanan dul kadına olum- 
suz bir imge yüklenir. Bunun sebebinin ise oldukça nedensel bir akıl yürütme olduğunu söyleyebiliriz. Zira şayet bir kadın iyi bir eş ise o kadını eşi boşamaz diye düşünülür. Yani boşanmış kadın için toplum tarafından 'otomatik olarak' kötü kadın hükmü verilir. Yine aynı akıl yürütmenin sonucu olarak boşanmış kadının, işveli, kurnaz, hilebaz, sahtekâr, çokbilmiş, plancı ve benzeri olduğu varsayılır. Nihayetinde bu toplumdaki boşanmış kadın hakkındaki, dolayısıyla 'kadın' hakkındaki tüm bu peşin hükümler, onun ne denli erkeğin tasarrufunda olduğunu göstermektedir.

131. "Dullukta yaptıklarını kızlıkta yapmış olaydın; belki dul kalmazdın."

132. "Bir kere evlenmiş yetmemiş, ikinciye kimse olmamış."

133. "Dul kadın işvesiyle tilkiyi kulübeye kıstırır."

134. “Üç kere doğum yapanla evlensen de boşananlarla evlenme.”

135. "Kız evlenirken dul halay çeker."

136. "Toplumun üç sınıfı kızdırılamaz, devlet memuru, alıcı ve dul kadın."

137. "Dul kadın yârdan sayılmaz."

Öte yandan dul kalmış kadınlarla ilgili onların çabalamalarının ne kadar değerli olduğunu ifade eden bazı atasözleri de mevcuttur. Özellikle kocası öldükten sonra çocukların eğitim ve yetiştirilmesi kendi sırtına yüklenen dul kadınlar övülmektedir. Çünkü böyle dul kadınların bütün zorluklara rağmen toplum için iyi evlatlar yetiştirmesi, toplumun geneli tarafından takdir edilmesi gereken bir ödev olarak görülmektedir.

138. “Dul kadın mehir istemiyormuş, ama şimdi sekizden biri ister."

139. "Dul kadın çabalar da bir sürü hayırlı çocuk yetiştirir."

140. "Dul kadın ailesini ustaca birarada tutar."

141. "Böyle değil, böyle olmaz, dul kadının oğlu beni dinlemez."

Bazı atasözlerinde ise dul kadının ikinci kere evlenmesi gerektiği söylenirken, evlenmediğinde de onlara yönelik negatif ifadelerin 
kullanıldığ1 tespit edilmiştir. Dul kadının ikinci kere evlenmek istemesi aşırıcılık olarak görülmüştür. Aynı zamanda dul erkeklerde durumun tam tersinin mevcut olduğu tespit edilmektedir; nitekim bir atasözünde eşi ölen erkeklere kız verilmesi tavsiye edilmiştir.

142. "Kadını, eşi ölene ver; öküzü öküzü ölene ver."

\subsection{Yaşlı Kadın Olgusu ile İlgili Atasözleri}

Kürt atasözlerine bakıldığında toplum tarafından her yaşlı kişinin akıl ve tecrübe sahibi sayılmadığı anlaşılır. "Yaşlılık ve bin ayıp." atasözünde olduğu gibi insan bu dönemde çoğunlukla sağlık durumundan kaynaklı olarak bunama ve iş yapma olanağı azaldığı için sıkıntılı bir yaşantı sürdürür. Ama "ögüut vermeyen yaşlıdan mir olmaz" atasözünde olduğu gibi yaşlı kişinin önemli işlerde akıl yürüttüğü için önemli olduğu ifade edilmektedir.

İncelediğimiz Kürt atasözlerinde, yaşlı kadın için genel olarak dırdırc1, geveze, engelci, ufak tefek ve önemsiz şeyler için ısrarcı kimse gibi anlamlara gelen nitelemeler kullanılmaktadır. Yaşlı kadının, çoğunlukla boş ve sürekli konuştuğu varsayıldığından sözlerinin pek önemsenmemesini telkin eden atasözlerine rastlanmaktadır.

143. "Yaşlı kadın daha kendi aşkını hatırlayamaz, ama beni ve yârimi çekemez."

144. "Sürü kaybolmuş, yaşlı kadın hâla kırmızı buzağıyı sorar."

145. "Ne koyun ağası davayla, ne de yaşlı kadınla ricayla."

146. "Şeytanın bir senede yaptıklarını yaşlı kadın bir günde yapar."

147. "Tekrarlama iyi değil, yaşlı kadın kabul değildir."

Bazı atasözlerinde ise yaşlı kadının kırsal hayattaki dirayetli ve azimli yaşamına ilişkin övücü ifadelere rastlamak mümkündür. Bu tür yaşlı kadınların toplum içeresinde olumlu bir imaja sahip olduğu görülmektedir.

148. "Yaşlı kadın dağa gider de kışlık odun getirir." 


\section{Atasözlerinde Kadınlık Tasavvuru}

Toplumda kadınlara ilişkin olumlu ve olumsuz görüşler bulunmaktadır. Her erkek kendi evinde bir kadın ister, ancak bu istek yalnızca kişinin keyfiyetine göre şekillenmez. Bir bakıma toplum değerleri ve ölçüleri doğrultusunda, erkeğin isteği toplum tarafından belirlenir.

149. "Kadın var ev yapar, kadın var ev yıkar."

150. "Kadın bal arısı gibidir, ya bal verir ya da iğnesini sokar."

151. "Kadının 40 çeşit işi olur, sadece ekmeğiyle hamuru bilinir."

152. "Kadının yaptığı yuvayı kimse yıkmaz."

Kürt atasözlerine göre kadın, akledemez ve sadece kendi güzelliğini önemser. Dolayısıyla kadın 'akılsız' olarak telâkki edilir.

153. "Aynanın karşına geçmedikçe kadın bir şey düşünmez"

Kadının başarılı bir idareci ya da iyi bir yol gösterici olamayacağı bir çok Kürt atasözünde ifade edilir. Belki de bugün dahi süregelen bu anlayışın tezahürlerini görmekteyiz. Nitekim kadınların yönetici pozisyonlarında hâlen erkeklere oranla daha az olması, bu anlayışla uyuşmaktadır.

154. "Kadını ağa yapmışlar, senede 7 kere keçi kırkmış."

155. "Kadına mülkünü teslim edenin eli boş kalır."

156. "Kadına sürüyü vermişler, kırk oğlaktan bir koç kalmış."

Yine incelenen bazı atasözlerinde kadının hep erkeğe bağımlı olduğu telkin edilmektedir. Yani kadın erkeğe muhtaç bir varlık olarak görülmektedir. Bunun bir uzantısı olarak evlenen kadınlar da doğum yapmadığı sürece aile içerisinde tam bir yer edinememiştir. Çünkü kadın erkeğin soyunu devam ettirme işlevini yerine getirememiş olarak düşünülmektedir. Genel olarak kadının baba, koca ya da erkek kardeş gibi bir erkeğe ait olması gerektiği görüşü hâkimdir diyebiliriz.

157. "Kimsesiz kadın küstah, kimsesiz erkek fakir olur."

158. "Evlat vermeyen kadın yabancıdır." 
159. "Atla pusat kimdeyse, kadın onundur."

160. "Başsız kadın devletsiz millet gibidir."

161. “Ha kocasız kadın, ha duvarsız ev!”

162. "Erkeksiz ev, suyu olmayan değirmen gibidir."

Bazı atasözlerinde ise kadının bir şekilde erkeği yönettiği ifade edilir.

163. "Erkek hayvana koşum takar, kadın da erkeğe."

164. "Erkeğin bahtı iyi bir kadından geçer."

165. "Erkek kadının sözüyle yola koyulur."

Bazı atasözlerinde ise kadından güvenilmez ve değersiz olarak bahsedilmektedir. İncelenen atasözlerine göre kadın, çenebaz olduğu için sır tutmayı beceremez. Bundan dolayı kadına inanılmaması gerektiği telkin edilir. Aksi hâlde kadının, kişinin yuvasını yıkacağı söylenir.

166. "Kadına ve kışa aldanan kendi evini yıkar."

167. “Gönlündekini karına söyleme."

168. "Kadın sinirlendiğinde ortada sır kalmaz."

169. "Adam ipe gitse, karısı incik boncuk ister."

Bazı atasözlerinde kadın şeytana benzetilmiştir. İncelediğimiz bazı atasözlerinde kadının işvesi ile şeytanın ayartması özelliklerinden dolayı birbirine benzetilmiştir.

170. "Şeytanı mektebe göndermişler; hocası kadın olmuş."

171. “Kadının işvesi, şeytanın şerri!"

172. "Kadın işvesiyle dağları devirir."

173. “Kadının gözünden iki gözyaşı damlar: birisi gamdan diğeri yalandan."

Bazı atasözlerinde kadının yerinde duramadığı gözünün hep d1şarda olduğu söylenir. Oysa erkek için 'dışarısı' hiç de uygunsuz bir yer değildir. Aksine erkeğin geçim kaygısı nedeniyle zaten hep 
dışarda olması gerektiği vurgulanır, hatta erkek ne kadar çok yere giderse o kadar değerlidir. Bu algının bazı çeşitlerini günümüzde de görebiliriz. Örneğin erkeğin mal mülk kazanmak için evinden ayrılması gayet makul bir davranış olarak algılanır.

174. "Kadın yeni ayakkabı almak için çıkar da bin ayakkabı eskitir."

175. "Adama eşin çok geziyor, hayırdır? Demişler, adam 'yok öyle bir şey; gezseydi bize de gelirdi demiş.'”

\section{Kadın Kimliği Hakkında İncelenen Atasözleri}

İncelenen Kürt atasözlerinden anlaşıldığı kadarıyla, Kuzey Irak Kürtlerinde kadının kimliği erkeğinkine nisbetle anlam kazanabilir. Bir kız çocuğu dünyaya geldiğinde, öncelikle 'babasının kızı' olarak toplumda bir yer edinir. Baba ocağından ayrılıp da evlenen kadın ise, toplumun bir alışkanlığı olarak; kocasının ismi, lakabı ya da mesleği ile ilgili türetilen bir isim ile çağrılır. Genel olarak, kocasının halk arasında yaygın olarak çağrıldığı şekliyle irtibatlandırılarak kadından bahsedilir. Yani nihayetinde halk arasında kadından; baba, koca, erkek kardeş gibi erkek akrabalarla ilişkilendirilerek bahsedilir. Böyle bir alışkanlık bize, kadının tek başına kendini temsil kabiliyetinin bulunmadığını göstermektedir, diyebiliriz. En azından böyle bir nedensel ilişki kurmak eldeki veriler doğrultusunda o kadar da yadırganmayacaktır. Hatta belki de bu durumdan kadınların da memnun olduğunu söyleyebiliriz. Nitekim birtakım atasözleri böyle bir gerçekliğe işaret etmektedir. Sonuçta bunun kadınlar tarafından da kabul edilen, kültürel bir alışkanlık olduğunu söyleyebiliriz.

176. "Ağa karısı desinler de öküzün boyunduruğunu da takarım."

177. "Her yerime çivilesinle ama yeter ki bana ağa karısı desinler."

178. "Kadın bir gecede Molla karısı oluverir."

İncelediğimiz bazı atasözlerinde kadının tamamen erkeğin tasarrufunda olduğunu görürüz. Erkek, kadın adına kararlar alır ve bunları uygular. Bu bağlamda kadının iradesi erkeğin elindedir, diyebiliriz. Dolayısıyla kadın, yaşamını idame ettirebilmek için büyük ölçüde bir erkeğe muhtaçtır. 
179. “Ev kadından sorulur, kadın da erkekten!"

180. "At, pusat, avrat sahibinin eline bakar."

Bazı atasözlerinde kadının erkeğe tam bağımlı olduğu düşüncesi işlenmektedir. Toplum içerisinde kadınlar eşleri tarafından nasıl tanitılırsa diğer insanların gözünde de o şekilde kabul edilir. Bazı deyişlere göre bu durumdan kadınlar da memnundur, diyebiliriz.

181. "Ağa bir kadına karımdır derse ahali ona ağa karısıdır der, ağa bu kadın kimdir derse ahali bu kadının adı da nedir der."

182. "Adam horozdur kadının üstünde yer alır."

183. "Adam mihmandar gibidir kadın onun takipçisidir."

5. Aile İçindeki Kadın Üyeler Arasındaki İlişkiler Hakkındaki Atasözleri

\subsection{Karıkoca İlişkileri Hakkında Atasözleri}

Karıkoca ilişkileri hakkında bulunan atasözleri incelendiğinde; özelikle kadının ev içinde önemli bir role sahip olduğu ve kocası ile ailesini birleştirici bir unsur olduğunu görürüz. Bunun yanı sıra iktidar ve otoritenin evin erkeğinde toplandığını söyleyebiliriz.

184. "Karı, kocanın eli ayağıdır."

185. "Adamı adam yapan da adamlıktan çıkartan da kadındır."

186. "Karısının rezil ettiği erkeği tüm dünya birleşse kurtaramaz."

187. "Eşi tarafından methedilen kadını, kimse aşağılayamaz."

188. "Karıkoca kavgası yatağa kadar sürer."

189. "Taş altında yatsa da karının yeri kocasının yanıdır."

Kürt geleneğinde, çoğunlukla evlilik, tek erkek ve tek kadın arasında (monogami) gerçekleşmektedir. Bu atasözlerindeki ifadelerde de açıkça görülebilmektedir. Bununla birlikte çok eşliliğin (poligami) yaygın olmasa da toplumda var olduğu tespit edilmektedir. Ama bu tür çok eşli evlilikler genellikle eskiden beri ağa ve zengin olanlarda görülmüş, toplumun çoğu tarafından tasdik edilmemiştir. 
190. "İki eşli adam, dizine kadar bataklığa batmıştır."

191. "Allah tektir ve ortağı yoktur, iki karılı erkeğin boş vakti yoktur."

192. "İki karılı erkeğin yüreği kevgir gibi delik deşiktir."

193. "Kuma, keklik de olsa istenmez."

\subsection{Anne Bağlamındaki Atasözleri}

Kadının toplumdaki karşılığını anlamak için baktığımız Kürt atasözlerinden bir kısmı da anneyle ilgilidir. Çocuk doğuran kadın, anne, toplumda oldukça önemli bir değere sahiptir. Çocuk sahibi olmayan aile için ise 'ocağı kör kalmış' ifadesi kullanılır. Bu minvalde kadının en değerli olduğu toplumsal konum, annelik müessesesidir.

Yine incelenen atasözlerine baktığımızda, anne ve babanın en önemli rolü çocuklarının düzgün ve terbiyeli yetiştirilmesi için gerekli ilgiyi göstermesidir. Çocuğuna güzel ahlâk ve öğüt vermekle mükellef anne-babanın hayırlı evlat sahibi olması da toplum için oldukça önemli görülmektedir.

194. "Allah'ın yardımıyla anam beni doğurur, babam da beni yetiştirir."

195. "Babanın sevgisi mezara kadar, annenin sevgisi ebedidir."

196. "Ana-babanın kötülüğü çocuğa sirayet eder."

Çocuk yetiştirmeyle ilgili atasözlerinin genelinde anneye hayatî bir önem atfedildiğini müşahede etmekteyiz. Deyişlerin genelinde çocuktan ve onun eğitiminden bahsedilirken, çocuğun anne ile ilişkisinin önemine değinilir. Burada annenin, yani kadının genel olarak ev işleri ile ilgilenmesi ve babanın ailenin geçimini sağlaması böyle bir iş bölümünü adeta zorunlu kılmaktadır. Çünkü kadın ev işleri ile uğraşırken aynı zamanda evdeki çocuğun ilk eğitimini de sağlamaktadır. Nihayetinde ev hanımı çocukla en çok vakit geçiren ebeveyndir. Büyük ölçüde bu rol dağılımı sebebiyle Kuzey Irak Kürt toplumunda, annenin, çocuğun eğitiminde en önemli unsur olduğunu görmekteyiz. Bu çerçevede Kürt atasözlerinde annenin özverisinin açıça sonsuz önemde olduğu görülmektedir. 
197. “Anne çocuğun yanında asla yaşlanmaz."

198. "Anne, çocuğunun ciğerini bilir."

Çocuğun yetiştirilmesinde annenin rolünün babadan önemli olduğunu ifade eden atasözleri bir hayli fazladır:

199. "Çocuk annesiz kalınca yetim olur."

200. “Anne ölürse baba da ölür."

201. "Çocuğu merak eden herkes anasını sorar, babadan sual olunmaz."

202. "Annenin tokadı, besindir çocuğa."

203. "Annenin sözünü dinlemeyenin gittiği yol yol değildir."

Annelik konusunda dikkat çeken bir başka mesele üvey anneliktir. Kürt atasözlerinde üvey anneden pek hoş bir şekilde bahsedilmez, hatta üvey annenin çoğunlukla kötü özelliklerinden dem vurulur. Elbette bu toplumun her kesiminin üvey anneleri yadırgadığ1 anlamına gelmez, ancak genel olarak üvey anneye dair de olumsuz bir imajin olduğu gerçeğini incelenen atasözlerinde görebilmekteyiz.

204. "Üvey anne, din düşmanıdır."

205. "Üvey anne Allah tanımaz."

206. "Bir eve üvey anne gelirse, çocuğun babası da üveyleşir."

\subsection{Ailenin Kadın Üyeleri Arasındaki İlişki (Gelin-Kaynana ve Gelin-Görümce)}

Aileden bahsedilen Kürt atasözlerinin geneline baktığımızda, aile kavramının çoğunlukla 'geniş aile' kavramına işaret ettiğini görmek mümkündür. Belki de atasözlerinde aile meseleleri bu yüzden daha yoğun bir şekilde karşımıza çıkmaktadır. Çünkü geniş ailenin sadece sayısal büyüklüğü bile bir çok ilişkiden ve dolayısıyla meseleden bahsetmeyi mümkün kılmaktadır. Örneğin, kaynana ile gelin arasındaki gerilimli ilişki sıkça söz edilen şeylerdendir. Bu muhtemelen çekirdek ailelerin yaygınlaşması ve ailelerin küçülmesiyle birlikte daha az mesele hâline gelen bir olgudur. Ancak yine de süregelen yaşam biçimi yine de bu tarz 
atasözlerinin bir şekilde hâlâ karşılığının olduğunu gösterebilmektedir. Nitekim günümüzde ailelerin tamamen çekirdek aile hâline geldiğinden bahsetmek de mümkün değildir. Belki geniş aile ilişkilerindeki kronik meselelerin daha farklı biçimlerde karşımıza çıtığından bahsetmek mümkündür. Bu bağlamda kadınların aile içindeki birbirleriyle olan mücadelesini konu edinen bir çok atasözüne rastlamak mümkündür.

207. “Ne zaman ki deve merdiven çıkar, o zaman gelinle kaynananin arasındaki sorun biter."

208. "Gelinde dil yokmuş, kaynanada iman yokmuş."

209. "Ne kaynanam var öldürsün beni, ne buzağım emsin beni."

210. “Ah be kaynana! Hiç mi gelinlik görmedin!”

211. "En iyi kaynana ölü kaynanadır."

212. "Kaynana gelininin yazın doğun yapmasını ister, kızınınsa da kışın."

213. "Kaynana yılan gibi gelinini sessizce takip eder."

214. "Gelin getirdik ki evimizi düzeltsin, ama o bizimle kavga eder."

215. "Oğlan büyüttüm elin kızı aldı, kız büyüttüm elin oğlu aldı."

Yine Kürt atasözlerinde gelin ve görümce ilişkileri ele alınırken de sorunlar ve çatışmalar ön plana çıkar. Bir taraftan da kumalar arasındaki sorunlar aile içindeki kadın çekişmelerine örnek olarak verilebilir. Nihayetinde kadının toplumsal konumunu anlamak için yalnızca erkek ile arasındaki ilişkiye bakmak yeterli değildir. Kadınların kendi arasındaki ilişkiler de toplumsal konumlarını anlamamızda önemli bir yer tutmaktadır.

216. "Gelin için görümcesiyle yaşaması ayakkabıda iğneyle gezmek gibidir."

217. "Kaynanaya esir düşmektense düşmana esir düşmek yeğdir."

218. "Kuma, kumayı güzelleştirir; elti, eltiyi hızlandırır." 


\section{Sonuç}

Kız çocuklarının atasözlerinde yetiştirilmesi ve korunmasının zor olduğu, özellikle önemli tercihlerinin anne ve babanın tasarrufunda olduğu ve dolayısıyla onların nazarında değerlerinin oldukça pragmatik olduğu söylenebilir. Aile içerisindeki konumu itibariyle kız çocuğunun birinci derecede önemli görülmediği, erkek evladın kız çocuğuna tercih edildiği çıkarımı yapılabilir. Kız ve anne ilişkileri hakkındaki atasözlerinde güçlü bir ilişkinin söz konusu olduğu da söylenebilir. Kürt toplumunda kız, istenilen ve elde edilen şey konumundadır ve doğurganlık önemli bir ölçüttür. Dolaysıyla kızların genç yaşta evlendirilmesi gerektiği tavsiyesinde bulunulmaktadır. Bunun nedeni herhangi bir erkeğe ilgi duymasın, erkeğin tuzaklarına düşmesin diye erken evlenmesi gerektiğinin düşünülmesidir. Öte yandan 'zamanında' evlenmeyen kız için kokmuş, çürümüş ve bozulmuş gibi olumsuz anlamlar yüklenmektedir. Bu çerçevede 'soylu' ve 'köklü' bir aileden kız alınması tavsiye edilirken aynı şekilde 'soysuz' olanlardan da uzak durulması gerektiği vurgulanmaktadır.

Genel olarak deyişlerden anladığımız kadarıyla Kuzey Irak Kürt toplumunda erkek ve kız çocuk arasında bir tür ayrımcılık yapıldığ1 görülmüştür. Kız çocukları burada duruma göre "önemli" ve "önemsiz" ya da "daha az önemli" olarak nitelendirilmektedir. Ancak erkek çocuk büyük oranda kalıcı bir zenginlik olarak görülmektedir. Babanın soyunu devam ettirirme potansiyeli erkek evladın, kız çocuğuna tercih edilmesine bir gerekçe olmuştur. Kızlar evleneceği için geçici evlatlar olarak değerlendirilir ve babanın mirasını talan etmekle itham olunurlar. Yine kızlar için erkek kardeşlerin çok büyük öneme sahip olduğu tespit edilmiştir. Aynı zamanda kızlar çocukları da erkek kardeşleri için ev içindeki hizmetleri sağladığı için değerli olabilmektedir.

Sürekli karşılaşılan bu negatif anlam yüklemesinin ataerkil bir toplumsal yapıdan kaynaklandığı göze çarpmaktadır. Kimi zaman kadın küçümsenmiştir, yüceltildiğindeyse kadın; temel olarak erkeğin işine yaradığı için önem kazanmıştır. Kadının görevi, yaşadığı ev ile sınırlıdır, kadının ev dışına gitmesi ve kadınların bir araya gelmesinin hoşa gidilmeyen bir durum olarak görüldü- 
ğü tespit edilmektedir. Bununla beraber bazı atasözlerinde manevi ve ahlaki ölçütler bakımından kadın değerli olarak görülmüştür. Bazı atasözlerinde ise kadın düşünmeyen ve kendi güzelliğine bakan, iktidarı ve üstünlüğü uygun görülmeyen zayıf ve duygusal davranan bir varlık olarak nitelendirilmiştir. Öbür taraftan kadınların erkeklere bağımlılığı temel hususlardan biridir. Yine bazı atasözlerinde kadın güvenilmez ve değersiz olarak nitelendirilirken şeytana dahi benzetilmiştir.

Kürt atasözlerinde kötü ve iyi kadın arasındaki ayrımın keskin olduğu söylenebilir. Erkeğin hakimiyeti dışına çıkan her kadın kötü kadın olarak görülmüştür. Kadınların çok ve boş konuşmaları da temel bir kanaattir. Sessiz kadın dahi kuşku duyulacak bir durumun habercisi olarak görülür. İncelenen atasözlerine göre kadınların şeytana benzetilmesi kadının kurnazlığından kaynaklanmaktadır. Bu minvalde kadının başına gelen şiddet olaylarının sorumlusu da yine kadının ta kendisidir, anlayışı hakimdir. Kadının utangaç ve namuslu olması gerekir. Kadın evin direğidir ve ev içindeki işlerle uğraşması gerekir, evin temizlik ve diğer işlerini kadınlar üstlenmelidir.

Kürt toplumunda, her şeyden önce genç ve bakire olan kızlarla evlenilmesi tavsiye edilir ve bu durum dul kadınların hor görülmesini kolaylaştırmıştır. Bakireliğin önemi dışında dul kadınlara ayrıca kötü hasletler de yakıştırılmıştır. Dul kadınlar atasözlerinde ikiye ayrılmaktadır. Eşi ölen dul kadın, buna olumlu anlam yüklenmektedir, çünkü bazen bu kadınlar tekrar evlenmeden çocuklarını büyütüp onlara terbiye vermektedir. Diğeri ise boşanan dul kadınlardır, bu tür dulluğa toplum tarafından oldukça olumsuz anlam yüklenmektedir.

Atasözlerinde yaşlı kadının gençlerin engelcisi, geveze, dırdırcı ve şeytana benzetildiği tespit edilmektedir. Genel olarak olumsuz ifadelerle yüklenildiğinden dolayı toplum içeresinde kabul görmediği dikkat çekmektedir. Kimi zaman özellikle kırsal alanda yaşayan yaşlı kadınlar, ömrünün sonuna kadar çabaladığı için toplum tarafından onlara karşı olumlu bir yaklaşım sergilendiği göze çarpmaktadır. 
Karıkocanın birlikte aile devamlılığını sağladığı ve birbirini tamamladığ1 görülmektedir. Annelik diğer sosyal ve biyolojik pozisyonlara göre kadının gördüğü en değerli statüdür, çünkü toplumsal cinsiyet rollerine göre iş bölümünden kaynaklanan ev içindeki işleri ve çocuk bakımının anneye bırakıldığı göze çarpmaktadır. Anneliğin karşılık beklemeyen şefkat ve sevgisinden dolayı fedakârlık isteyen bir şey olarak nitelendirildiği de görülmektedir.

Yine kadın kimliğinin erkekler üzerinden kurulan bir kimlik olduğu tespit edilmektedir. Bu çerçevede bir kadının eşinin statü olarak aldığı her şey, hemen aynı şekilde kadının da statüsü haline gelmiştir. Kimi zaman atasözlerinde kadınların tam olarak erkeğin elinde olduğu açık bir şekilde ifade edilmiştir. Tüm bunlardan hareketle, Aktaş'ın (2013) ifade ettiği gibi, erkek ve kadın kimliğinin oluşturulmasında toplum tarafından onlara yönelik tanımlamaların kimliğin oluşumunda önemli rol oynadığı söylenebilir. $\mathrm{Bu}$ da ziyadesi ile aile ve toplum müesseseleri tarafından gerçekleştirmektedir. Bu doğrultuda toplumun içerisinde var olan değer, örf, norm ve kültürün kuralları çerçevesinde, toplumsallaşma sürecinde bireye kimlik kazandırılmaktadır.

Kürt kadın kimliği her toplumda olduğu gibi dönemlere göre de değişmektedir. Elbette burada Kuzey Iraktaki Kürt kadınlarının toplum tarafından nasıl algılandığı atasözleri üzerinden anlaşılmaya çalışılmaktadır. Kadının kimliğini oluşturan unsurlar kültürel ve sosyal durumlardan kaynaklanmaktadır. Bu açıdan toplumun tarihinde yer alan feodalizmin kadın üzerinde büyük etkisi bulunmaktadır. Kürt toplumunun da şimdiye kadar Ortadoğu'daki toplumlarda var olduğu gibi ataerkil bir toplum olduğunu açıkça söyleyebiliriz. Çoğunlukla Kürt toplumu muhafazakâr, geleneksel ve ataerkil bir toplumdur. Toplumda var olan rol ve sorumluluklar bakımından, kadınlar ve erkekler arasında, aynı zamanda erkekler arasında ise büyüklüğe ve küçüğe göre görev ve sorumluluk verilmektedir. Aile içindeki ve dişındaki egemenlik ve iktidar en başta erkeklerin ve babanın elinde bulunur. Muhafazakârlık Kuzey Irak'ta toplum içinde kır ve kentlere göre, hatta kentler arasında bile değişebilmektedir. 


\section{Kaynakça}

Albayrak, N. (2009). Türkiye Türkçesinde Atasözleri (1. b.). İsatanbul : Kapı Yayınları.

Ali, O. (1972). Pendi Kurdi (1. b.). Baxdad: Dezgay Roşnbiri u Blawkrawy Kurdi.

Artun, E. (2015). Türk Halk Edebiyatına Giriş (10. b.). Adana: Karahan Kitabevi Yayınları.

Gramsci, A. (2013). Kültür ve İdeolojik Hegemonya. J. C. Alexander içinde, kültür ve toplum (N. Yavuz, Çev., s. 61-70). İstanbul: Boğaziçi Üniversitesi Yayınevi.

Güleç, H. (2002). Halık Edebiyatı (1. b.). Konya: Çizgi Kitabevi Yayinları.

Haviland, W. \& diğerleri. (2008). Kültürel Antropoloji (1. b.). (D. Erguvan, Çev.) İstanbul: Kaknüs Yayınları.

Helebceyi, H. (2012). Pendi Gelan (2. b.). Suleymani: Xaney Çap w Pexşi Renma.

Kaplan, M. (2006). Kültür Ve Dil (22. b.). İstanbul: Dergah Yayınları.

Kurt, İ. (1991). Türk Atasözlerinde Psikolojik Bir Yaklaşım (1. b.). Ankara: Kültür Bakanlığı Yayınları.

Lek, H. (2012). Gwlbjerek le Pendi Kurdi (4. b.). Suleymani: Ketebxaney Bextyari.

Mengü, G. (2003). Dil-Kültür İlişkisine Antropolojik Bir Bakış. B. Yediyıldız içinde, Dil, Kültür ve Çağdaşlaşma (s. 15-27). Ankara: Hacettepe Üniversitesi Atatürk İlkeleri ve İnkılap Tarihi Enstitüsü.

Morin, E. (1995). Avrupa'yı Düşünmek (1. b.). (Ş. Tekeli, Çev.) İstanbul: Alfa Yayınları.

Osman, K. (2010). Pende Bawakan (3. b.). Suleymani: Xaney Çap w Pexşi Renma.

Reşaş, H. (2010). Pendi Kurdi (1. b.). Dohuk: Kori Zanyari Kurdstan w Akadimyay Kurdi.

Saussure, F. (2013). Göstergeler ve Dil. J. C. Alexander, \& S. Seidman içinde, Kültür Ve Toplum (N. Yavuz, Çev., 1. b., s. 70-84). Istanbul: Boğaziçi Ünüversitesi Yayınları. 
Şarazuri, A. (2010). Pendi Peşinani Kurd (2. b.). Suleymani: Ketebxaney Şex Razay Talabani.

Tezcan, M. (2008). Kültürel Antropoloji (1. b.). Ankara: Maya Akademi Yayınları.

Tok, N. (2003). Kültür, Kimlik ve Siyaset (1. b.). İstanbul: Ayrıntı Yayınları.

Ünalan, Ş. (2012). Dil Ve Kültür (5. b.). Ankara: Eskiyeni Yayınları.

Xal, M. (2014). Pendi Peşinan (5. b.). Suleymani: Blawkrawey Çapxaney Şıvan.

Yıldırım, A. \& Şimşek, H. (2013). Sosyal Bilimlerde Nitel Araştırma Yöntemleri (9. b.). Ankara: Seçkin Yayıncılık. 